Open Access

\title{
Digital informal learning among Chinese university students: the effects of digital competence and personal factors
}

Tao He* and Chang Zhu

\author{
* Correspondence: \\ tao.he2016@gmail.com \\ Department of Educational \\ Sciences, Vrije Universiteit Brussel, \\ Pleinlaan 2, B-1050 Brussel, Belgium
}

\begin{abstract}
Although informal learning with digital technology is a near universal activity among university students, the processes that influence and regulate digital informal learning (DIL) is not given. Meanwhile, digital competence is of growing importance for our current information society, and also it plays an essential role in the process of digital informal learning. However, the measurement for digital competence is a critical challenge for further understanding its development in practice. This study contributes to our understanding of students' digital informal learning behavior by examining the effects of digital competence, along with other personal factors. Partial least square (PLS) path modeling was employed to explain the interaction and effects of these factors on students' DIL. Students from a large-sized public university in Beijing participated in this study. The results revealed students' personal innovativeness and digital competence are mediated by attitude to DIL to affect students' DIL, and all these personal factors demonstrated important direct effects on students' DIL.

Additionally, significant gender differences between female and male students in certain aspects of digital competence were observed.
\end{abstract}

Keywords: Digital competence, Digital informal learning, PLS path modeling, Structural equation modeling

\section{Introduction}

Engagement with digital technology has become a central part of students' daily life. This trend suggests a transformative way of approaching learning and studying, not only inside but also outside of university. However, digital technologies are not being fully exploited in education and training systems. In higher education, learners now are expecting more personalized, collaborative and better managed links between formal learning and informal learning (Dabbagh \& Kitsantas, 2012; Margaryan, Littlejohn, \& Vojt, 2011). Previous educational studies have focused on the implementation of digital technology in formal settings, while the investigation of individual constructs on informal learning with digital technologies are limited requiring that this area of research needs to be fully addressed (Chan, Walker, \& Gleaves, 2015; Song \& Lee, 2014).

Recent research studies are paying more attention to digital informal learning in higher education since it is a new trend of ubiquitous learning among university students in today's digital age (Chan et al., 2015; Huang \& Oh, 2016). These tend to focus on a single

(c) The Author(s). 2017 Open Access This article is distributed under the terms of the Creative Commons Attribution 4.0 International License (http://creativecommons.org/licenses/by/4.0/), which permits unrestricted use, distribution, and reproduction in any medium, provided you give appropriate credit to the original author(s) and the source, provide a link to the Creative Commons license, and indicate if changes were made. 
digital informal learning resource as a case study (Chan et al., 2015; Song \& Lee, 2014), or look at developing a framework of digital informal learning for university students' professional development on their early college experiences (Huang \& Oh, 2016). Digital informal learning features a digital media enriched environment in which students could broaden their learning experiences with digital technologies, digital informal learners learn more the further along with the curation process they progress (Song \& Lee, 2014; Ungerer, 2016). However, empirical research is needed to improve our understanding of the nature and extent of digital informal learning (Huang \& Oh, 2016).

In addition, young people are developing digital competence that corresponds to important cognitive processes of digital learning in informal learning environments. Although, there are already a lot of frameworks and discourses around digital competence, such general theoretical frameworks will not be sufficient as the digital competence develops (Calvani, Fini, Ranieri, \& Picci, 2012; Janssen et al., 2013; Littlejohn, Beetham, \& McGill, 2012). Hence, we require more developed assessment tools to measure digital competence need to be developed. Moreover, prior studies claim that digital competence may impact individual's performance with digital technology in informal learning environments (Meyers, Erickson, \& Small, 2013; Ungerer, 2016). Therefore, it is crucial to know that the role of digital competence in students' digital informal learning.

Being that informal learning with digital technology is learner centered in a personal learning environment, so the key personal factors should be investigated (Chan et al., 2015; Dabbagh \& Kitsantas, 2012). Studies have found that student's personal trait factors have a major influence on mobile media for informal learning in higher education, especially the personal innovativeness (Cheng, 2014; Liu, Li, \& Carlsson, 2010). As an additional personal factor and a mediator, Attitude to technology usage has shown a significant impact upon university students' learning with technology (Lai, Wang, \& Lei, 2012). As an important mediator to informal learning with technology, attitude may mediate the impact of personal innovativeness and digital competence or digital literacy to students' informal learning behavior. Which means that digital competence and personal innovativeness may directly influence digital informal learning as well as indirectly impact students' informal learning behavior with technology through attitude (Meyers et al., 2013; Ungerer, 2016).

Overall, few studies have accounted for the conceptualization of relationships among personal factors from a learner perspective and how these factors work together on digital informal learning. The anchoring question guided this study is how does digital competence interact with personal innovativeness and attitude to digital informal learning to enable digital informal learning behaviors? Therefore, this study aims to investigate the interactions and effects of digital competence, personal innovativeness and attitudes to digital informal learning on digital informal learning behaviors among university students.

\section{Literature review and theoretical framework}

\section{Digital informal learning}

Previous studies have noted that informal learning mostly occurs without a specific time and place. Moreover, informal learning does not specify the subject or materials required for effective study (Livingstone, 2000; Tudor, 2013). Researchers have proposed some features of formal, non-formal and informal learning. These features suggest that formal learning usually takes place in institutions (e.g. schools or universities) 
and is often assessed whilst informal learning is more unstructured, voluntary and is learner-led; non-formal refers to structured out of school learning such as in school-led museum field trips or visits to science centers, thus possessing aspects of formal and informal learning (Gilbert, 2010; Marsick \& Watkins, 2001). It may then be concluded that the distinguishing feature of informal learning is learner control: control over the individual's learning process and goal setting.

The access to the internet has been increasing both in formal school settings and private life. As a result, digital technologies are used more intensively in students' life. Digital technology makes informative content easier to find, to access, to manipulate and remix, and to disseminate. Each of these steps are central to teaching and learning. Together, they constitute a dynamic process of digital learning (McGeveran \& Fisher III, 2006).

Furthermore, digital informal learning has been defined in terms of technology-mediated learning opportunities and environments in informal learning settings. Meanwhile, individuals can access these resources voluntarily without any predetermined learning objectives in mind, while individuals can customize them according to individuals' learning needs (Huang \& Oh, 2016). For the purposes of, we will conceptualize digital technology for learning within an informal learning context as digital informal learning (DIL). More specifically, DIL has been operationalized for university students' use in terms of fitting with several aspects of informal learning behavior.

\section{Digital competence}

Digital Competence has been identified as one of the eight key competences for Lifelong Learning by the European Union (European Commission, 2006) alongside Digital Literacy, Media Literacy, ICT Literacy, Information literacy, and Internet Literacy. All of these competences are used to identify and analyze students' ability to achieve with digital technology (Hatlevik \& Christophersen, 2013). Digital literacy and digital competence are used as synonyms usually (Calvani et al., 2012). These concepts overlap one other to a greater or lesser extent. Digital Literacy has been defined as a framework for a number of complex and integrated sub-disciplines or literacies comprised of skill, knowledge, ethics and creative outputs in the digital network environment (Calvani, Cartelli, Fini, \& Ranieri, 2009).

Digital competence is often used in different contexts: 1) policies related to development for innovation and education. 2) a convenient term for teachers to understand students' ability in school. 3) concept discussed and explored in research articles (Ferrari, 2012). Although there are different variants of the concept and various dimensions of digital competence within different contexts, the agreement is that digital literacy is broader than ICT literacy and includes other elements such as information literacy, media literacy and visual literacy (Calvani et al., 2012). Hence, the research focus needs to shift from mere technical mastery towards the higher-order cognitive skills and socio-ethical-relational issues related to the use of technologies (Calvani et al., 2012). In sum, digital competence should include students' ability to use technology for accessing and consuming information; moreover, digital competence also shows how students make use of technology to process, acquire, and evaluate gathered information (Hatlevik \& Christophersen, 2013).

When it comes to the assessing of students' digital competence, it is important to provide the correct descriptors to specify the presence of the term into precise areas. Calvani (2009) summarized digital competence as a combination of concrete and 
unquantifiable skills. Furthermore, they have developed a digital competence framework that emphasizes the co-existence of dimensions characterized both on the technological, cognitive and ethical levels dimensions and the integration of the relevant skills within these dimensions (Calvani et al., 2012).

This study has employed the theoretical framework by Calvani (2012) since it is empirical tested and can be easily implemented to measure youths' digital competence in an instant way This framework comprises of three technological dimension, cognitive dimension and ethical dimensions, all of with sub-dimensions, to be taken into account as the main competence areas in the majority of the frameworks reviewed.

\section{Personal factors related to digital informal learning}

Previous studies on adoption technology for learning have focused on external factors related to technology such as interface design, ease of use and usability (Lai et al., 2012; Lopez-Fernandez \& Rodriguez-Illera, 2009). Other studies have claimed that when driving informal learning more attention should be given to the personal factors' impact, such as individual's personal competence for technology use; yet participants also need specific skills and positive attitude to technology on a certain level to be able to participate successfully (Dabbagh \& Kitsantas, 2012). However, there has been insufficient empirical research to explain the structural relationships between personal competence, personal innovativeness and attitude to technology on students' digital informal learning. Hence, this study examines the influence of the digital competence and other important personal factors (personal innovativeness and attitude to technology) on digital informal learning behavior.

Attitude toward behavior refers to an individual's behavioral tendency with positive or negative feelings, attitude to technology use is an important personal factor when investigating the adoption of digital technology in e-learning process, mobile learning and online learning (Celik \& Yesilyurt, 2013; Lai et al., 2012). In the informal learning context, the process of learning does not need to be pre-established, as students have the chance to find and even set up environments according to their individual needs and premises. Thus, attitude to digital technology plays an important role for acceptance and success.

Personal innovativeness is defined as the level of willingness to accept new technology, highly innovative individuals are active information seekers about new ideas and tend to develop a more positive attitude and intention to technology acceptance. Moreover, Personal innovativeness also reduces anxiety around computer use, comprising an open attitude to change, which would result in higher tendency to technology use in virtual environment (van Raaij \& Schepers, 2008). Previous study has also found that personal innovativeness, as one of the personal characteristics, has a significant influence on user satisfaction and intentions to continue using of mobile learning (Joo, Lee, \& Ham, 2014). In the informal learning context, students initiate unstructured learning activities and, as a key personal factor, personal innovativeness would play a greater role in enabling DIL.

The research model in Fig. 1 has been created to address digital informal learning and related key personal factors. This model addresses our main research question: how do these factors (attitude to digital informal learning, digital competence, personal innovativeness) work together on students' digital informal learning? The effects of these factors will be reviewed in the following review of the related literature on technology-enhanced learning. 


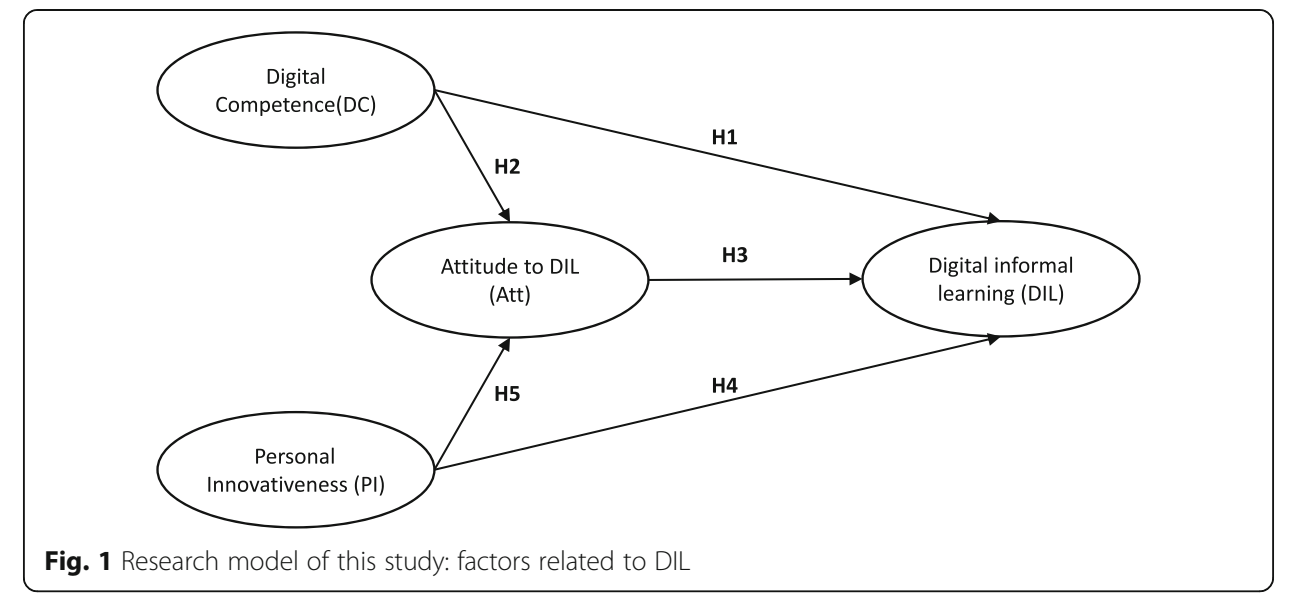

The effects of digital competence on DIL

Based on the literature review above, digital competence is students' ability to use technology in order to consume and access information. Digital competence includes how people make use of technology to process, acquire and evaluate gathered information, for further production and communication of information with digital tools or media. It is closely related to students' computer or ICT self-efficacy which emphasis on users' perception of their capabilities to use ICT to achieve intended outcomes (Venkatesh, Morris, Davis, \& Davis, 2003). Previous studies found that computer self-efficacy has a significant influence on students' adoption of digital tools or application for learning (Hatlevik \& Christophersen, 2013; McCoy, 2001; Park, 2009; Park, Nam, \& Cha, 2012). Moreover, empirical study has shown that computer self-efficacy is positively associated with attitude to technology (Celik \& Yesilyurt, 2013). Therefore, we replace ICT or computer perceived self-efficacy with digital competence, the more advanced construct, and hypothesize similarly.

H1: Digital competence (DC) is positively associated with students' digital informal (DIL) behavior.

H2: Digital competence (DC) is positively associated with attitude to digital informal learning (DIL).

\section{The effects of student attitude on DIL}

Attitude to technology use, despite not deemed influential in mandatory technology adoption contexts (Davis, Bagozzi, \& Warshaw, 1989), is argued to be very relevant in informal learning environments such as students' voluntary adoption of technology (Saadé \& Galloway, 2002). Studies on students' intentions to accept e-learning or use virtual learning systems and individual technological applications did find that attitude to technology use is an essential mediator for learning with technology (El-gayar \& Moran, 2006; Hsu, 2012; Lai et al., 2012). We hence hypothesize in the same way.

H3: Attitude to digital informal learning (Att) is positively associated with students' digital informal learning (DIL) behavior. 
The effects of personal innovativeness on DIL

Since the learning with digital technology in informal context is an informal learning process which features the learner control. Previous studies argue that in informal learning, where learners set their own goals, intrinsic motivation is often higher than in formal settings where goals are pre-set (Jones, Scanlon, \& Clough, 2013). Hence, Informal learning with digital technology depends on individual willingness to use as much as the other extrinsic factors related digital technology itself. Results from information system studies show that personal innovativeness as a key personal trait factor that affects intention to use informational technology (Venkatesh \& Davis, 2000). The current empirical studies of learning with technology in higher education found students' personal innovativeness has a significant influence on mobile learning (Cheng, 2014; Liu et al., 2010). Therefore, we hypothesize in the same way.

H4: Personal innovativeness (PI) is positively associated with students' digital informal learning (DIL) behaviors.

H5: Personal innovativeness (PI) is positively associated with attitude to digital informal learning.

\section{Methods}

Sample

The present study applied a quantitative approach with cross-section design, a structured paper-based survey was designed according to the framework mentioned above. Participants were 235 university students at a large comprehensive research university in Beijing. A total of 357 students volunteered to take pencil and paper based survey from May 2014 to July 2014. And finally, 235 valid responses were retained, among whom 137 were female and 98 were male, more details see Table 1 . Prior to answering the survey, students were given a definition of digital informal learning as aforementioned. And also, the digital technologies were illustrated: Digital technologies including the Internet online communities, online games, online audio/video, online chatting tools, blogs, collaborative sites like wikis, social networking sites, multimedia software, mobile devices like smart phones, PDAs and MP3 players.

\section{Instruments}

\section{Digital informal learning scale}

This study has used literature research based on the iDCA (Instant Digital Competence Assessment) instrument framework to define and concretize the sub-elements of the digital competence (Calvani et al., 2009, 2012). However, a new scale has been developed with 31 items using a self-evaluated module solution that provides the opportunity with a self-report questionnaire.

The digital competence scale includes technological, cognitive and ethical dimensions relating to types of skills and knowledge. The technological dimension includes three sub-dimensions: 1) Visual literacy (VL) refers to useful knowledge for recognizing icons, symbols, interfaces. 2) Understanding Technological Concepts (UTC) refers to Knowledge relating to common technological functions, computer potential and concepts and procedures pertaining to logic. 3) Trouble Shooting (TS) refers to the operative knowledge useful in solving common technological problems. Most of this knowledge is acquired through practice (Calvani et al., 2012). 
Table 1 Demographic information and descriptive results of DIL

\begin{tabular}{lll}
\hline Variables & Frequency & Percent \\
\hline Gender & 137 & $58.3 \%$ \\
Female & 98 & $41.7 \%$ \\
Male & & \\
Age (year) & 172 & $73.2 \%$ \\
$18-22$ & 59 & $25.1 \%$ \\
$23-27$ & 4 & $1.7 \%$ \\
above 27 & & \\
Education level & 195 & $83 \%$ \\
undergraduate & 40 & $17 \%$ \\
postgraduate & & \\
Most frequently used & & $49.4 \%$ \\
digital technology for DIL & 116 & $93.2 \%$ \\
Desktop & 219 & $31.9 \%$ \\
Laptop & 75 & $83.0 \%$ \\
Table Pc & 195 & $30.2 \%$ \\
Smartphone & 164 & $16.6 \%$ \\
Mp3,4 and iPod & 39 & $10.6 \%$ \\
E-reader & 25 & \\
Others & & \\
\hline
\end{tabular}

The cognitive dimension pertains to high-order cognitive skills and has three subdimensions: 1) Organising and connecting textual and visual data (OCTV) refers to skills required when semantically relevant links should be established or data is labelled or transformed into graphics or vice versa. 2) Organising structured data (OSD) refers to the skills required when analysing data, recovering data and making inferences within structured data systems. For example, the use of archives, spreadsheets. 3) Information Search (IS) refers to the critical evaluation of information (Calvani et al., 2012).

The ethical dimension pertains to the ability to interact adequately with others, which is in turn related to types of interactions with digital media and their significant effects on online responsibility and citizenship (Calvani et al., 2012). This ethical dimension has two subdimensions: 1) Staying safe online (SSO) refers to personal privacy. 2) Respect for others (RO) refers to having adequate knowledge of social and emotional literacy.

\section{Digital competence scale}

This study defined and concretized the sub-elements of the digital competence through literature research, based on the iDCA (instant digital competence assessment) instrument framework (Calvani et al., 2009, 2012). However, a new scale developed with 31 items using selfevaluate module solution that provides the opportunity to have a self-report questionnaire.

The digital competence scale has technological, cognitive and ethical dimensions, which relate to particular types of skills and knowledge. The technological dimension includes three sub-dimensions: 1. Visual literacy (VL) refers to useful knowledge for recognizing icons, symbols, interfaces. 2. Understanding Technological Concepts (UTC) refers to Knowledge relating to common technological functions, computer potential and concepts and procedures pertaining to logic. 3. Trouble Shooting (TS) refers 
to operative knowledge that helps in solving common technological problems. Most of this knowledge is acquired through practice (Calvani et al., 2012).

The cognitive dimension pertaining to High-order cognitive skills also has three subdimensions: 1. Organizing and connecting textual and visual data (OCTV) refers to skills required when semantically relevant links have to be established or data has to be labeled or transformed into graphics or vice versa. 2. Organizing structured data (OSD) refers to the skills required when analyzing data, recovering data and making inferences within structured data systems. For example, the use of archives, spreadsheets. 3. Information Search (IS) refers to evaluate information critically (Calvani et al., 2012).

The ethical dimension pertains to the aspects related to the ability of adequately interacting with others, which involves specific implications regarding to types of interactions by the digital media with significant effects on online responsibility and citizenship (Calvani et al., 2012). This ethical dimension has two sub-dimensions: 1) Staying safe online (SSO) refers to personal privacy. 2) Respect for others (RO) refers to the knowledge of social and emotional literacy.

Attitude to DIL scale For the purposes of this study, the DIL attitude scale comprises of three items (Davis et al., 1989; Venkatesh et al., 2003). The Attitude to DIL scale involves testing individual's positive or negative feelings about conducting informal learning with digital technology. Here, students were asked to evaluate how often they approach digital technology in search of learning aids in an informal learning context. For instance, one might state, "In informal learning context, I often actively seek new technologies to help with learning needs; I keen on using technologies to facilitate learning outside formal learning settings".

Personal innovativeness scale The personal innovativeness scale has three items (Liu et al., 2010). We can define personal innovativeness as the level of willingness to accept new technology; hence it is conceptualized in terms of three items expressing individual levels of interest and intention towards informal learning with technology. For instance, "If I heard about a new digital technology for learning, I would look forward to experimenting with it in informal learning context".

Overall, all the scales chosen are based on previous studies, although the wording of some of the measures was changed to adapt to the informal learning context. Meanwhile, the survey instrument has been pre-tested for content analysis. However, this study was not focused on digital technology for informal learning as the students were told to report the informal learning scenarios where they take digital technologies for learning. The items were slightly modified to suite the context and translated into Chinese. Afterwards, wording and translation changes were included in the questionnaire. Each item was measured using a five-point Likert scale, ranging from strongly disagree to strongly agree.

\section{Results}

\section{Validation of instruments}

The confirmatory factor analysis (CFA) was conducted to confirm and refine the factor structure of the digital competence scale. In this study, CFA was used to test the second order three-factor model of digital competence scale, and the first order of sub-scale model fit. A variety of fit indices were used to test the model fit. An adequate model fit is represented by GFI, AGFI and CFI values that are greater than 0.90 (Hoyle, 1995), and a RMSEA 
value below 0.05 is good and below 0.08 is acceptable (Byrne, 2001). Table 2 shows the results of CFA for all sub-scales and the overall digital competence scale. After removing some items and modifying the model to improve the model fit according to the modification indices, the overall results showed a satisfactory fit to the data. These results indicated that our multi-dimensional digital competence scale model has a good fit to the sample test. To assess the reliability of the scale, Cronbach's Alpha was computed, all sub-scales Cronbach's scores are greater than 0.74 (in Table 3) which shows each of digital competence subscales have a good internal consistency reliability.

Except the scale of digital competence, in order to validate other adopted scales from the literature in model, the confirmatory factor analysis was analyzed by using the partial least squares (PLS) path modeling to assess scales reliability and validity. PLS is a component-based structural equation modeling technique that has minimal demands on measurements scales, sample size, and residual distributions (Chin, 1998). For this study, PLS was chosen because of its minimal requirements regarding sample size and its prediction capability, the commonly accepted guideline for determining the minimum sample size is that it should be at least 10 times the number of predictors in the most complex relationship of the model (Fornell \& Larcker, 1981; Gefen, Rigdon, \& Straub, 2011). In our research model, the most complex relationship comprised the digital informal learning construct with three predictors. Thus, applying the aforementioned guideline would yield a minimum sample size of 30 for this study, and the sample size $(N=235)$ is good to meet the required criteria for analysis.

The reliability and validity of the constructs in the measurement model should be assessed by internal consistency, convergent validity and the discriminant validity. Three criteria were applied to assess convergent validity: internal consistency, indicator reliability, and average variance extracted (AVE). To ensure internal consistency, must ensure the reliability (Cronbach's $\alpha$ coefficients) and composite reliability. A scale was considered adequate if the alpha value was at least 0.70 (Chin, 1998). And composite reliability should be greater than 0.70 (Chin, 1998). Both thresholds were exceeded for all constructs. Table 4 lists the constructs, the related items, and the factor loadings. Indicator reliability is satisfied since each item of indicator loading is higher than 0.70 on the related construct (Chin, 1998). And last, all AVE exceeded the suggested value of .50 (Chin, 1998).

Discriminant validity was checked to show that all of the constructs (Digital informal learning, Digital competence, Attitude to DIL, Personal innovativeness) were different from each other. Fornell and Larcker (1981); Gefen and Straub (2005) state that discriminant validity is evaluated by considering the correlation among the constructs. The square root of AVE values of each construct should be higher than all of the correlation values of constructs (Fornell \& Larcker, 1981; Gefen \& Straub, 2005). The Table 5 shows that all of the constructs were different from each other. The diagonal

Table 2 Confirmatory factor analysis

\begin{tabular}{llllll}
\hline & CMIN/DF & GFI & AGFI & CFI & RMSEA \\
\hline Technological & 1.17 & 0.94 & 0.90 & 0.99 & 0.04 \\
Cognitive & 1.23 & 0.95 & 0.90 & 0.99 & 0.04 \\
Ethical & 1.12 & 0.95 & 0.92 & 0.99 & 0.04 \\
Overall Model & 1.37 & 0.96 & 0.92 & 0.99 & 0.05 \\
\hline
\end{tabular}


Table 3 Internal consistency reliability

\begin{tabular}{llll}
\hline Scale & Sub-scale & Cronbach's Alpha & N of Items \\
\hline Technological & 1. Visual Literacy & 0.76 & 4 \\
& 2. Trouble Shooting & 0.83 & 3 \\
3. Understanding Tech Concepts & 0.85 & 5 \\
Cognitive & 1. Organizing and Connecting & 0.85 & 3 \\
& Textual and Visual data & & 3 \\
& 2. Organizing Structured Data & 0.74 & 6 \\
3. Information Research & 0.89 & 4 \\
& 1. Staying Safe Online & 0.87 & 3 \\
\hline
\end{tabular}

shows the square root of AVE values of each construct and these values were higher than the other correlation values among the constructs.

\section{University students' DC, DIL, attitude to DIL and personal innovativeness}

After all the scales were validated, the descriptive results of students' DC and DIL, their attitude to DIL and personal innovativeness were analyzed, the mean and standard deviation were reported for each scale and sub-scale of the whole sample, the results are presented in Table 6 . The results show that Chinese university students maintain a high level of staying safe online (SSO) of awareness $(M=3.92, S D=0.83)$ both for males $(M$ $=3.79, S D=0.85)$ and females $(M=4.01, S D=0.71)$. In contrast, the organizing structural data skills $(\mathrm{OSD})(M=3.02, S D=0.86)$ appear to be the lowest level compared with other sub-dimensions of digital competence. Female students have the highest SSO $(M=4.02, S D=0.79)$ awareness and lowest OSD $(M=3.04, S D=0.85)$ skills. However, male students have the highest IR $(M=3.68, S D=0.84)$ skills and lowest UTC $(M$ $=2.91, S D=0.53$ ) skills.

We then conducted an independent sample t-test to determine whether there are significant differences between female and male students in relation to different dimensions of digital competence and digital informal learning. We also applied the independent sample t-test to test gender differences in attitudes to DIL and personal innovativeness; more details are to be found in Table 4. By analyzing gender variances,

Table 4 Measurement of constructs (with reliabilities)

\begin{tabular}{|c|c|c|c|c|c|}
\hline Latent Construct & Indicators & $\begin{array}{l}\text { Number of } \\
\text { items }\end{array}$ & $\begin{array}{l}\text { Factor } \\
\text { loading }\end{array}$ & $\begin{array}{l}\text { Cronbach's } \\
\text { alpha }\end{array}$ & $\begin{array}{l}\text { Composite } \\
\text { reliability }\end{array}$ \\
\hline \multicolumn{2}{|c|}{ Attitude to digital informal learning } & 3 & $>0.74$ & 0.76 & 0.86 \\
\hline \multicolumn{2}{|c|}{ Personal innovativeness } & 3 & $>0.79$ & 0.77 & 0.86 \\
\hline \multirow[t]{3}{*}{ Digital competence } & ICT Skills & 12 & 0.85 & 0.85 & 0.92 \\
\hline & Cognitive Skills & 12 & 0.94 & & \\
\hline & $\begin{array}{l}\text { Ethical } \\
\text { Knowledge }\end{array}$ & 7 & 0.84 & & \\
\hline \multirow{3}{*}{$\begin{array}{l}\text { Digital informal } \\
\text { learning }\end{array}$} & Cognitive & 4 & 0.81 & 0.88 & 0.92 \\
\hline & Meta-cognitive & 4 & 0.94 & & \\
\hline & $\begin{array}{l}\text { Social \& } \\
\text { Motivation }\end{array}$ & 4 & 0.91 & & \\
\hline
\end{tabular}


Table 5 Discriminant validity

\begin{tabular}{lllll}
\hline 1. Attitude to digital informal learning & $\mathbf{0 . 8 3}$ & & & \\
2. Digital competence & 0.66 & $\mathbf{0 . 8 8}$ & $\mathbf{0 . 8 9}$ & \\
3. Digital informal learning & 0.73 & 0.73 & 0.81 & $\mathbf{0 . 8 3}$ \\
4. Personal innovativeness & 0.71 & 0.76 & 0.71 \\
\hline
\end{tabular}

Diagonals represent the square root of average variance extracted, while the other matrix entries represent the squared correlations

we found significant differences between female and male students in terms of Trouble Shooting (TS) $(t=-1.98, p<0.05)$ and Organizing and Connecting Textual and Visual Data (OCTV) $(t=2.05, p<0.01)$ sub-scales.

The results for the other sub-scales of digital competence, reveal that there are no differences between female and male students. Moreover, no significant differences were found within the three aspects of digital informal learning. These results show that female and male students tend to demonstrate similar behavior in digital informal learning. Meanwhile, no gender differences were found in students' attitude to DIL and their personal innovativeness. These results indicate that female and male students demonstrate similar attitudes and personal innovativeness towards DIL, even if it would appear that male students have slightly higher scores on these two scales.

\section{Hypothesis testing}

Having established the reliability, convergent validity, and discriminant validity of all the constructs in the model, the next step is to test the structural model for the hypothesized paths by using a PLS bootstrap sampling method to estimate the path coefficients. The structural model results demonstrate path coefficients for each hypothesized path, while the corresponding $t$-values that denote the significance of the

Table 6 Independent sample t-test and descriptive results of DC, DIL, Attitude to DIL and Personal innovativeness

\begin{tabular}{|c|c|c|c|c|c|c|}
\hline & \multicolumn{2}{|c|}{ Female $(N=137)$} & \multicolumn{2}{|c|}{ Male $(N=98)$} & \multirow[b]{2}{*}{ t } & \multirow{2}{*}{$\begin{array}{l}\text { Total }(N=235) \\
\text { Mean }(S D)\end{array}$} \\
\hline & Mean & SD & Mean & SD & & \\
\hline \multicolumn{7}{|l|}{ Aspects of DC } \\
\hline UTC & 3.08 & 0.51 & 2.91 & 0.53 & 1.94 & $3.03(0.53)$ \\
\hline$V L$ & 3.72 & 0.80 & 3.52 & 0.91 & 1.37 & $3.66(0.84)$ \\
\hline TS & 3.30 & 0.93 & 3.62 & 0.94 & $-1.98^{*}$ & $3.42(0.94)$ \\
\hline OCTV & 3.65 & 0.82 & 3.34 & 0.93 & $2.05^{*}$ & $3.54(0.87)$ \\
\hline OSD & 3.04 & 0.85 & 2.91 & 0.84 & 0.85 & $3.02(0.86)$ \\
\hline $\mathbb{I R}$ & 3.67 & 0.74 & 3.68 & 0.83 & -0.09 & $3.68(0.78)$ \\
\hline SSO & 4.01 & 0.79 & 3.79 & 0.85 & 1.51 & $3.92(0.83)$ \\
\hline $\mathrm{RO}$ & 3.38 & 0.71 & 3.60 & 0.75 & 1.88 & $3.40(0.74)$ \\
\hline \multicolumn{7}{|l|}{ Aspects of DIL } \\
\hline Cognitive & 3.67 & 0.80 & 3.48 & 0.82 & 1.81 & $3.59(0.81)$ \\
\hline Meta-cognitive & 3.39 & 0.89 & 3.40 & 0.83 & 0.07 & $3.40(0.87)$ \\
\hline Social \& motivation & 3.42 & 0.86 & 3.51 & 0.84 & 0.82 & $3.46(0.85)$ \\
\hline Attitude to DIL & 3.51 & 0.91 & 3.60 & 0.86 & 0.74 & $3.55(0.89)$ \\
\hline Personal innovativeness & 3.61 & 0.88 & 3.69 & 0.87 & 0.72 & $3.57(0.84)$ \\
\hline
\end{tabular}


coefficients along with $R^{2}$ values for the dependent variables of Digital Informal Learning (DIL) explained by the three independent variables: Attitude to DIL (Att), Digital competence (DC) and Personal innovativeness (PI).

As shown in Fig. 2, all the hypothesized paths are significant at differing levels. The H1 represents DC and has a positive association with DIL $(\beta=0.21, p<0.05)$, compared with PI's positive association with DIL at $\mathrm{H} 3(\beta=0.46, p<0.001)$. PI shows the highest path weight, indicating that PI is a more important antecedent than DC. The attitude to DIL is an important mediator because DC and PI have significant positive association Att, while Att has a significant association with DIL are all supported. There is hence a two-way effect relationship where DC and PI have a direct effect on DIL, while DC and PI have indirect effects on DIL through Att.

In terms of DIL and attitude to DIL, the R square in this model were 0.72 and 0.54 respectively. The attitude to DIL, personal innovativeness, digital competence elements explained $72 \%$ of the total variances for digital informal learning behavior. Digital competence and personal innovativeness explained $54 \%$ of the total variances in attitude to digital informal learning, while our research model explains more than $50 \%$ of total variance endogenous dependent latent variable indicate a good explanatory power (Chin, 1998).. The overall conclusion to draw is that the present model holds a good predictability and explanatory power for university students' digital informal learning behaviors.

\section{Effects analysis}

The total effect on a given variable is the sum of the respective direct and indirect effects. Possible associations among variables could be identified by the examining indirect effect, direct effect and total effect. Using the empirical results outlined above, we derived the association between two constructs with all these effects, presented in Table 7. In the context of DIL, the results show that all these individual factors were the significant antecedent factors to students' digital informal learning.

The order established for the total effects of all these factors from great to small was personal innovativeness $(\beta=0.59, p<0.001)$, digital competence $(\beta=0.28, p<0.01)$ and attitude to DIL $(\beta=0.26, p<0.01)$. The indirect effect and direct effect of digital competence on DIL were 0.07 and 0.21 respectively. While personal innovativeness had a

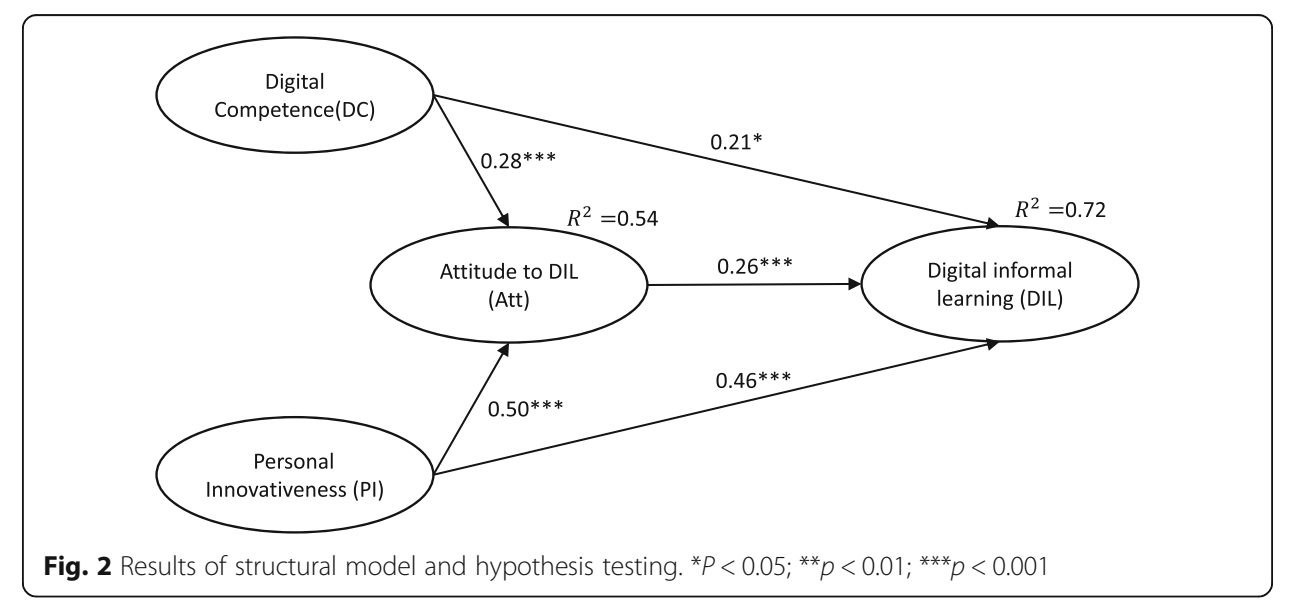


Table 7 Effects analysis results

\begin{tabular}{|c|c|c|c|c|c|c|}
\hline & Attitude & & & Digital ir & al learnin & \\
\hline & Standarc & Deffi & & Standaro & coefficien & \\
\hline & D & । & $\mathrm{T}$ & $\mathrm{D}$ & I & T \\
\hline Attitude to DIL & N & $\mathrm{N}$ & N & $0.26^{* *}$ & $\mathrm{~N}$ & $0.26^{* *}$ \\
\hline Digital Competence & $0.28^{* *}$ & N & $0.28^{* *}$ & $0.21^{* *}$ & $0.07^{* *}$ & $0.28^{* *}$ \\
\hline Personal innovativeness & $0.50^{* * *}$ & N & $0.50^{* * *}$ & $0.46^{* * *}$ & $0.13^{* * *}$ & $0.59^{* * *}$ \\
\hline
\end{tabular}

$D$ Direct effects, $I$ indirect effects, $T$ Total effects

${ }^{*} P<0.05,{ }^{* *} P<0.01,{ }^{* * *} P<0.001$

0.13 indirect effect and 0.46 direct effect on DIL. These findings reveal that all these three factors are largely in predicting DIL since the effect size is greater than the recommended value of 0.15 (Chin, 1998).

Concerning attitude to DIL, personal innovativeness had greater direct and total effect $(\beta=0.50, p<0.001)$ on it compared with digital competence $(\beta=0.50, p<0.001)$, while personal innovativeness was identified as the largest determinant on attitude to DIL. Therefore, all the exogenous latent variables had significant effects on at these two endogenous latent variables. These results revealed personal innovativeness to be the most important variable in influencing DIL. However, digital competence and attitude to DIL were also considered important since the effect size is relative large.

\section{Discussions and conclusions}

\section{Digital informal learning}

The present study examined the personal factors influencing students' digital informal learning behaviors, a three influential factors mediation model was approached to explain how digital competence interact with other highlighted factors affecting DIL in response to the anchoring question. The proposed mediation model highly explained students' DIL behaviors since a large variance $(72 \%)$ of DIL was explained by this model. The results showed that students' individual factors, including attitude to DIL, digital competence and personal innovativeness are significant direct determinants of students' digital informal learning. Furthermore, the attitude to DIL is a significant mediator, which also suggests that there is a need to boost students' personal attitude to DIL by promoting university students' digital competence and encourage personal innovativeness.

This study has revealed a high comfort level among students with digital technologies alongside a reasonably similar student comfort level with several uses of digital technology for informal learning. The descriptive results of DIL showed students are more get involved in cognitive learning with digital technology than other aspects of informal learning, while students appear to be more inclined to enhance understanding and expand their knowledge of discipline. However, students perform all these informal learning activities with a relatively high engagement of DIL in general. Therefore, using digital technology to assist learning in personal informal learning context is more universal, while the shift towards a transformation of learning with digital technology is inevitable in the informal learning context.

The study showed there are no significant differences among varying aspects of DIL which including learning activities related to cognitive learning, meta-cognitive 
learning, social and motivation learning. One possible clue is that female and male university students are engaging digital technologies in a trend towards homogenization which is that perhaps stronger than before. Likewise, the prior study also showed that no significant differences between male and female university students on time of computers for daily use in informal learning settings (Gabriel, Campbell, Wiebe, MacDonald, \& McAuley, 2012).

\section{Digital competence and its effects on DIL}

In terms of digital competence, this study confirms the hypothesis that university students' digital competence has a positive association with students' DIL, while students with higher level of digital competence tend to more get involved in DIL. Prior studies fund that students' digital literacy does not have significant effects on university students' technology use for learning and claims that, in the context of education, the basic technology skill is no longer a major obstacle for most students (Lai et al., 2012). In contrast, this study shows digital competence has a significant and medium effects on DIL since digital informal learning features are learner- centered and digital competence still matters in learner controlled informal personal context.

In addition, the study has attempted to contribute to the understandings of digital competence specifically for university students by developing and validating a selfassessment measure scale. The development of digital competence for university students presents an essential step in the development of the theories concerning digital competence and informal learning with digital media. The result revealed that the proposed digital competence scale had satisfying psychometric properties. Overall, these findings appear to be a good and instant measure of university students' digital competence.

The study also revealed that there are gender differences on different subscales of digital competence which is in line with a traditional view of males as being more digitally competent than females (Markauskaite, 2006; Tømte \& Hatlevik, 2011). However, no significant differences have been found on most subscales of digital competence, which confirms the previous results that female and male students are equal in terms of digital competence (Hatlevik \& Christophersen, 2013; Markauskaite, 2006).

\section{The effects of personal factors on DIL}

The present study has shown that personal innovativeness is the most influential personal factor, students who have higher personal innovativeness have higher levels of involvement of digital informal learning. Moreover, students' personal innovativeness has a major influence on attitude to DIL. These findings are consistent with studies in personal innovativeness within mobile learning (Liu et al., 2010).

Moreover, students with higher personal innovativeness tend to have more positive attitude to DIL. Given that our findings support that the existence of personal innovativeness as a personal trait factor, innovative learners may develop more positive beliefs on new digital technologies, manifest as a positive attitude towards technology use. In this case, they would be more inclined to digital informal learning.

The present study also implied that students who have positive attitudes toward digital informal learning have a greater intrinsic motivation to take on digital informal 
learning. These findings concur with similar previous studies that attitude to technology use was found to be a significant predictor on students' technology adoption for learning (El-gayar \& Moran, 2006; Lai et al., 2012; Park, 2009).

\section{Limitations and implications}

This study has a few limitations. First, sampling only took place in one university in China, whereas larger and more diverse samples should be used for future investigation. It is possible that students who were more comfortable with digital technology opted to participate in the study. Furthermore, female students outnumbered male students in participating in this study. Hence, the sample may somewhat over- represent the female group, even if the independent sample T-test has revealed no significant difference in all sub-dimensions of digital informal learning between two gender groups.

Moreover, it might be helpful for further research to investigate the digital informal learning of users from different age groups and cultural backgrounds as well as looking at specific digital tools for informal learning. Lastly, in addition to the individual variables examined in this study, future research needs to consider other various external factors within the social context affecting students' informal digital learning behavior.

Despite the limitations, this study has identified and clarified the key factors behind digital informal learning from an individual context perspective. However, in order to blend students' formal learning into informal learning context in higher education, researchers and educators need better to understand students' digital informal learning by emphasizing students' individual factors: attitude to DIL, digital competence and personal innovativeness. Future research on informal learning with technology can build on the findings of this research and offer greater insights on the individual factors. They should further investigate external context effect such as social influence interacts with these key factors to affect digital informal learning.

Furthermore, this validated model may not only be applied to explain students' technology use in informal learning context, but can also be used to predict the possible reasons for the lack of acceptance of learning technology from the perspective of individual context. Digital competence has been clearly defined and concreted in a multidimensional way, which makes evaluation of the role of digital competence in practice more sufficient, while a concrete scale design should be applied in future study related to digital competence. Personal innovativeness has been shown the most significant direct and indirect effects on DIL, demonstrating that personal traits have an important impact on student's autonomy of informal learning with technology use.

This research study concludes that the adoption of learning technology innovations in informal learning context is different from that of a mandatory context such as classroom setting. As a self-directed, self-controlled approach to more implicit and unstructured learning, extra attention should be given to personal traits factors when it is applied to informal learning contexts. The study has shown the value of including digital competence in studies of informal learning with digital technology. This approach has contributed new data to the growing body of research on digital competence development, and further highlighted digital informal learning is individual context centered and self-directed in nature. 


\section{Appendix}

Digital competence scale

\section{Technological Dimension}

Visual Literacy (VL):

1. I can use some software programs to deal with data visualization

2. I can use a certain software program to edit picture

3. I can use a certain software program to make video

Trouble shooting (TS):

1. I can use a variety of programs to deal with Antivirus problem for computer

2. I can deal with computer system problems

3. I can deal with software problems by searching online

Understanding Technical Concepts (UTC):

1. I am able to use at least one operating system skillfully (e.g. windows, OSX, Android, IOS, etc.)

2. I am able to operate at least a personal computer related hardware (desktop, laptop, tablet device or smartphone device)

3. I am able to use social media well

4. I am able to use some photo and video sharing tool well

5. I am able to use a variety of APPs

\section{Cognitive Skills dimension}

Organizing and connecting textual and visual data:

1. I can represent a text with a graph by digital tools

2. I can represent hierarchical classes with digital tools

3. I can identify the keywords well in a digital text very well

Organizing structured data:

1. I can organize data in a table by variety digital tools

2. I can find missing values in a table of digital context

3. I can use digital technologies to design my plan or schedule

\section{Information Research:}

1. I am quite confident at searching information online what I need

2. I am quite confident at searching information on a certain database

3. I have a strong awareness of credibility of information when search online

4. I have a strong awareness of reliability of information when search online

5. I often consider the reliability of information online when I quote or share it

6. I often consider the credibility of information online when I quote or share it

\section{Ethical Knowledge dimension}

Staying safe online:

1. When I surf online, I have awareness of Privacy (personal information, personal Photos, etc.)

2. When I deal with online payment, I am always aware of the safety issue.

3. When I see online content that makes me feel uncomfortable, unsafe or worried, I will leave it or take an action. 


\section{Respect for others:}

1. I often post pictures with my friends on the internet without their permission (reverse)

2. I have awareness of online bullying and behave myself decent online

3. I have awareness to comment or communicate with others online in a rational way

Digital informal learning scale: (report the learning behaviors in digital informal learning environments, all items are stem from the statement "in digital informal learning contexts, I often...")

\section{Cognitive:}

1. I often use digital technologies to enhance my understanding of school course materials in informal learning contexts.

2. I often use digital technologies to expand knowledge of discipline

3. I often use digital technologies to keep informed of the development in the discipline

4. I often use digital technologies to engage in self-expression

\section{Metacognitive:}

1. I often use digital technologies to seek learning strategies and tips

2. I often use digital technologies to help myself to monitor learning progress

3. I often use digital technologies to expand learning opportunities

4. I often use digital technologies to seek engaging learning experiences

\section{Social and Motivation:}

1. I often use digital technologies to sustain motivation in learning

2. I often use digital technologies to elicit support and help

3. I often use digital technologies to engage in constructive activities

4. I often use digital technologies to collaborate with people for learning

\section{Attitude to digital informal learning scale:}

1. In informal learning contexts, I often go to digital technologies to seek learning aids and help on my own

2. In informal learning contexts, I often actively seek new technologies to help with learning needs

3. I keen on using technologies to facilitate learning outside formal learning settings

\section{Personal innovativeness scale:}

PI1: I like to experiment with new digital technology for informal learning

PI2: If I heard about a new digital technology for learning, I would look forward to experimenting with it in informal learning context

PI3: Among my peers, I am usually the very first to try out new digital technology for informal learning

Funding

Funding this research is provided by China Scholarship Council. 


\section{Authors' information}

Prof. Dr. Chang Zhu working at the Department of Educational Sciences, Vrije Universiteit Brussel. The research of Chang Zhu covers innovative teaching and learning processes as well as the individual, institutional and cultural variables that affect the adoption of educational innovations, especially in online and blended learning. She is project leader for several international research projects and cooperation projects, including VLIR-UOS projects and Erasmus Mundus projects supported by the European Commission.

Tao He is a Ph.D researcher working at the Department of Educational Sciences, Vrije Universiteit Brussels. He focuses on factors affecting the adoption of digital technology both in formal and informal education. His main research interests are digital competence, informal learning with digital media, cross-cultural analysis of online education.

\section{Competing interests}

We have read and understood the journal policy on declaration of interests and declare that we have no competing interests.

\section{Publisher's Note}

Springer Nature remains neutral with regard to jurisdictional claims in published maps and institutional affiliations.

Received: 22 August 2017 Accepted: 29 November 2017

Published online: 22 December 2017

\section{References}

Byrne, B. M. (2001). Structural equation modeling with AMOS, EQS, and LISREL: comparative approaches to testing for the factorial validity of a measuring instrument. International Journal of Testing, 1(1), 55-86.

Calvani, A., Cartelli, A., Fini, A., \& Ranieri, M. (2009). Models and instruments for assessing digital competence at school. Journal of E-Learning and Knowledge Society-English Version, 4(3), 183-193.

Calvani, A., Fini, A., Ranieri, M., \& Picci, P. (2012). Are young generations in secondary school digitally competent? A study on Italian teenagers. Computers \& Education, 58(2), 797-807.

Celik, V., \& Yesilyurt, E. (2013). Attitudes to technology, perceived computer self-efficacy and computer anxiety as predictors of computer supported education. Computers \& Education, 60(1), 148-158.

Chan, N. N., Walker, C., \& Gleaves, A. (2015). An exploration of students' lived experiences of using smartphones in diverse learning contexts using a hermeneutic phenomenological approach. Computers \& Education, 82, 96-106.

Cheng, Y.-M. (2014). Exploring the intention to use mobile learning: the moderating role of personal innovativeness. Journal of Systems and Information Technology, 16(1), 40-61.

Chin, W. W. (1998). Issues and opinion on structural equation modeling. MIS Quarterly, 22(1), 1.

Dabbagh, N., \& Kitsantas, A. (2012). Personal learning environments, social media, and self-regulated learning: a natural formula for connecting formal and informal learning. The Internet and Higher Education, 15(1), 3-8.

Davis, F. D., Bagozzi, R. P., \& Warshaw, P. R. (1989). User acceptance of computer technology: a comparison of two theoretical models. Management Science, 35(8), 982-1003.

El-gayar, O. F., \& Moran, M. (2006). College students' acceptance of tablet PCs: an application of the UTAUT model. In 36th annual meeting of the Decision Sciences Institute (DSI), (pp. 2845-2850).

European Commission (2006). Recommendation of the European Parliament and of the council of 18 December 2006 on key competences for lifelong learning. Official Journal of the European Union, 394, 10-18.

Ferrari, A. (2012). Digital competence in practice: An analysis of frameworks. JRC Technical Reports. Institute for Prospective Technological Studies, European Union. Retrieved from http://jiscdesignstudio.pbworks.com/w/file/fetch/ 55823162/FinalCSReport_PDFPARAWEB.pdf.

Fornell, C., \& Larcker, D. F. (1981). Evaluating structural equation models with unobservable variables and measurement error. Journal of Marketing Research (JMR), 18(1), 39-50.

Gabriel, M., Campbell, B., Wiebe, S., MacDonald, R., \& McAuley, A. (2012). The role of digital technologies in learning: expectations of first year university students. Canadian Journal of Learning and Technology, 38(1), 1-18.

Gefen, D., Rigdon, E. E., \& Straub, D. (2011). An update and extension to SEM guidelines for administrative and social science research. MIS Quarterly, 35(2), iii-iA7.

Gefen, D., \& Straub, D. (2005). A practical guide to factorial validity using Pls-graph: tutorial and annotated example. Communications of AlS, 2005(16), 91-109.

Gilbert, J. K. (2010). Learning science in informal environments: people, places, pursuits. International Journal of Science Education, 32(3), 421-425.

Hatlevik, O. E., \& Christophersen, K.-A. (2013). Digital competence at the beginning of upper secondary school: identifying factors explaining digital inclusion. Computers \& Education, 63, 240-247.

Hoyle, R. H. (1995). Structural equation modeling: concepts, issues, and applications. Journal of Marketing Research, 34, 412-419.

Hsu, H. (2012). The acceptance of Moodle: an empirical study based on UTAUT. Creative Education, 3, 44-46.

Huang, W.-H. D., \& Oh, E. (2016). Retaining disciplinary talents as informal learning outcomes in the digital age: an exploratory framework to engage undergraduate students with career decision-making processes. In V. C. X. Wang (Ed.), Handbook of research on learning outcomes and opportunities in the digital age, (pp. 402-420). Hershey: IG Global. doi:10.4018/978-1-4666-9577-1.ch018.

Janssen, J., Stoyanov, S., Ferrari, A., Punie, Y., Pannekeet, K., \& Sloep, P. (2013). Experts' views on digital competence: commonalities and differences. Computers \& Education, 68, 473-481 http://doi.org/10.1016/j.compedu.2013.06.008

Jones, A. C., Scanlon, E., \& Clough, G. (2013). Mobile learning: Two case studies of supporting inquiry learning in informal and semiformal settings. Computers \& Education, 61, 21-32. 
Joo, Y. J., Lee, H. W., \& Ham, Y. (2014). Integrating user interface and personal innovativeness into the TAM for mobile learning in cyber university. Journal of Computing in Higher Education, 26(2), 143-158 http://doi.org/ 10.1007/s12528-014-9081-2.

Lai, C., Wang, Q., \& Lei, J. (2012). What factors predict undergraduate students' use of technology for learning? A case from Hong Kong. Computers \& Education, 59(2), 569-579.

Littlejohn, A., Beetham, H., \& McGill, L. (2012). Learning at the digital frontier: a review of digital literacies in theory and practice. Journal of Computer Assisted Learning, 28(6), 547-556.

Liu, Y., Li, H., \& Carlsson, C. (2010). Factors driving the adoption of m-learning: An empirical study. Computers \& Education, 55(3), 1211-1219.

Livingstone, D. W. (2000). Researching expanded notions of learning and work and underemployment: findings of the first Canadian survey of informal learning practices. Internation Review of Education, 46(6), 491-514.

Lopez-Fernandez, O., \& Rodriguez-IIlera, J. L. (2009). Investigating university students' adaptation to a digital learner course portfolio. Computers \& Education, 52(3), 608-616 http://dx.doi.org/10.1016/j.compedu.2008.11.003.

Margaryan, A., Littlejohn, A., \& Vojt, G. (2011). Are digital natives a myth or reality? University students' use of digital technologies. Computers \& Education, 56(2), 429-440.

Markauskaite, L. (2006). Exploring differences in trainee teachers' ICT literac: does gender matter? Australasian Journal of Educational Technology, 22(1), 445-455.

Marsick, V. J., \& Watkins, K. E. (2001). Informal and incidental learning. New Directions for Adult and Continuing Education, 2001(89), 25.

McCoy, C. W. (2001). The relationship of self-directed learning, technological self-efficacy, and satisfaction of adult learners in a digital learning environment. Tuscaloosa: University of Alabama.

McGeveran, W., \& Fisher III, W. W. (2006). The digital learning challenge: obstacles to educational uses of copyrighted material in the digital age. SSRN eLibrary.

Meyers, E. M., Erickson, I., \& Small, R. V. (2013). Digital literacy and informal learning environments: an introduction. Learning, Media and Technology, 38(4), 355-367.

Park, S. Y. (2009). An analysis of the technology accept ance model in understanding university students' behaviora intention to use e-learning. Educational Technology \& Society, 12, 150-162.

Park, S. Y., Nam, M.-W., \& Cha, S.-B. (2012). University students' behavioral intention to use mobile learning: evaluating the technology acceptance model. British Journal of Educational Technology, 43(4), 592-605.

Saadé, R. G., \& Galloway, I. (2002). Understanding intention to use multimedia information Systems for Learning. Issues in Informing Science and Information Technology, 10.

Song, D., \& Lee, J. (2014). Has web 2.0 revitalized informal learning? The relationship between web 2.0 and informal learning. Journal of Computer Assisted Learning, 30(6), 511-533 http://doi.org/10.1111/jcal.12056.

Tømte, C., \& Hatlevik, O. E. (2011). Gender-differences in self-efficacy ICT related to various ICT-user profiles in Finland and Norway. How do self-efficacy, gender and ICT-user profiles relate to findings from PISA 2006. Computers and Education, 57(1), 1416-1424.

Tudor, S. L. (2013). Formal - non-formal - informal in education. Procedia - Social and Behavioral Sciences, 76, 821-826.

Ungerer, L. M. (2016). Digital Curation as a Core competency in current learning and literacy: a higher education perspective. The International Review of Research in Open and Distributed Learning, 17(5).

van Raaij, E. M., \& Schepers, J. J. L. (2008). The acceptance and use of a virtual learning environment in China. Computers \& Education, 50(3), 838-852.

Venkatesh, V., \& Davis, F. D. (2000). A theoretical extension of the technology acceptance model: four longitudinal field studies. Insitute for Operations Research and the Management Sciences, 46(2), 186-204.

Venkatesh, V., Morris, M. G., Davis, G. B., \& Davis, F. D. (2003). User acceptance of information technology: toward a unified view. MIS Quarterly, 27(3), 425-478.

Submit your manuscript to a SpringerOpen ${ }^{\circ}$ journal and benefit from:

- Convenient online submission

- Rigorous peer review

- Open access: articles freely available online

- High visibility within the field

- Retaining the copyright to your article

Submit your next manuscript at $\gg$ springeropen.com 